\title{
Endoscopy-guided surgery of an atrio-esophageal fistula after failure of self-expandable metal stents
}

A 34-year-old man presented at the emergency department with syncope and atrial fibrillation. He had undergone atrial fibrillation ablation 3 weeks earlier. He was initially treated with anti-arrhythmic agents but developed seizures. A computed tomography scan revealed air embolisms on the brain and an atrioesophageal fistula in the mediastinum ( Fig.1). Because of hemodynamic instability, surgeons asked the Gastroenterology Department to place an esophageal stent.

A pediatric gastroscope was used to pass the guidewire. A completely covered selfexpandable metal stent (Boston Scientific, Marlborough, Massachusetts, USA) was placed using only radiological guidance. The insufflation bottle was disconnected to avoid unnoticed insufflation. Two days later a coaxial stent was placed because the first stent had migrated proximally (> Fig.2). Seven days later, after initial improvement, the second stent also migrated proximally. The patient's condition continued to worsen, so it was decided to close the fistula surgically.

Surgery was performed with extracorporeal circulation. Cardiovascular surgeons repaired the defect in the atrium ( Fig.3a) with endoscopic guidance from the esophagus ( $\triangleright$ Fig. $\mathbf{3 b}$ ). Endoscopy discovered another previously undetected fistula. A new completely covered metal stent was placed to protect the esophagus at the end of the procedure ( $\vee$ Video 1 ). The following day, the patient developed cardiac and renal failure. The patient's condition deteriorated and he consequently died.

Atrio-esophageal fistula is a rare but serious complication of atrial fibrillation ablation [1,2]. Patients are at risk of air embolism and mediastinitis. For this reason, endoscopy is contraindicated and urgent surgery is preferred as treatment. Endoscopy can be helpful to guide treatment during surgery, and in this case, a hidden

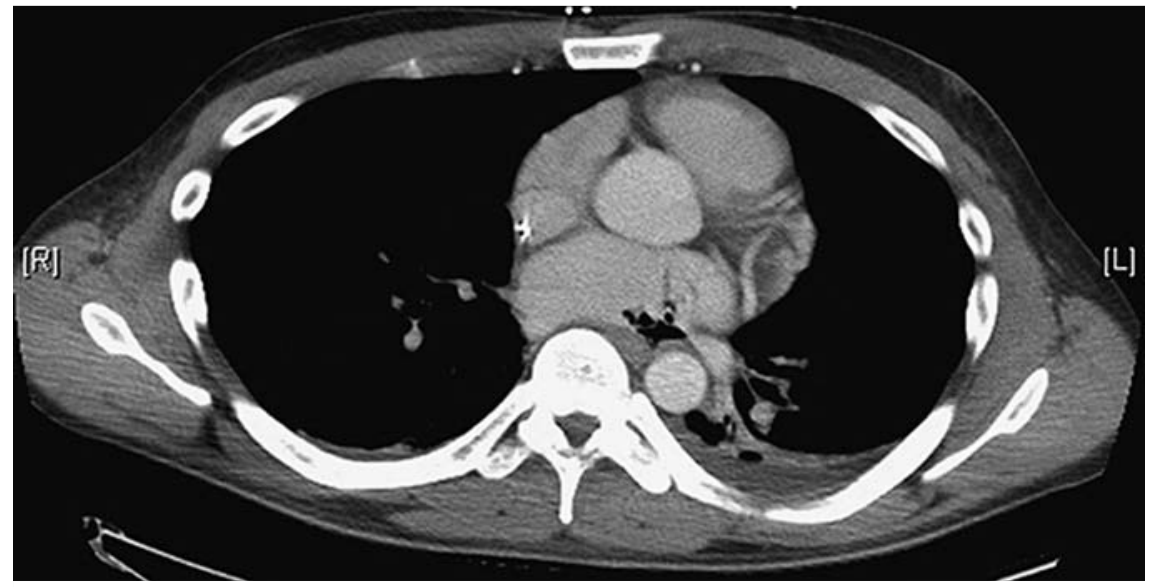

- Fig. 1 Computed tomography showing air in the mediastinum caused by an atrio-esophageal fistula.

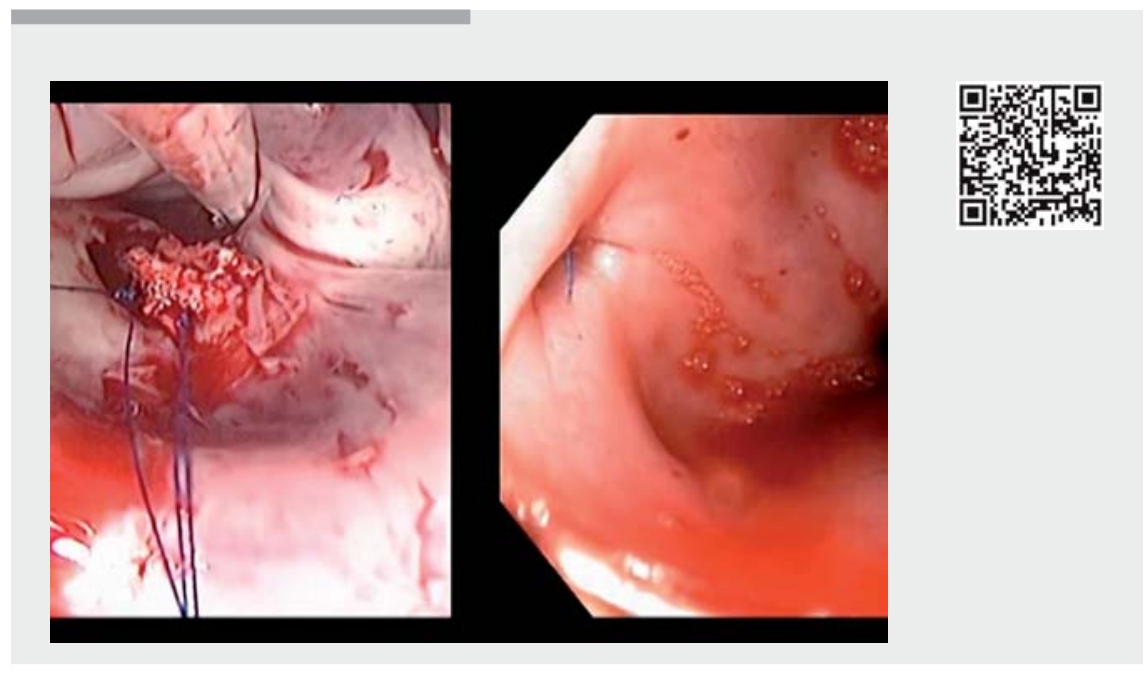

Video 1 Computed tomography revealed air in the mediastinum after atrial fibrillation ablation. After migration of two metal stents, it was decided to operate on the patient with endoscopic guidance.

fistula was discovered. Previous cases describing endoscopic treatment with stents with fatal result have been reported $[3,4]$. Successful treatment of other complications of atrial fibrillation ablation, such as esophageal perforation or esophago-pericardial fistula with stents, has been described.
Endoscopy_UCTN_Code_CCL_1AB_2AC_3AH

None
Competing interests 


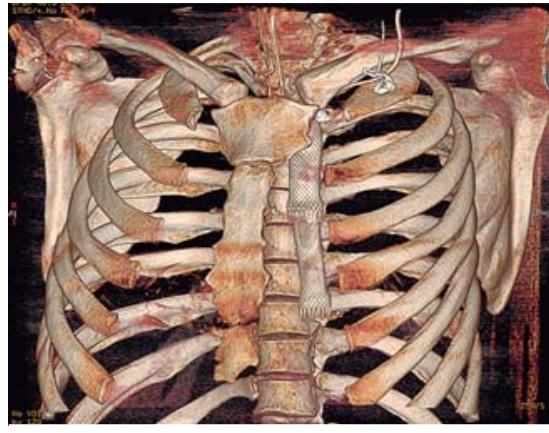

Fig. 2 Reconstruction of the two metal stents covering the atrio-esophageal fistula.
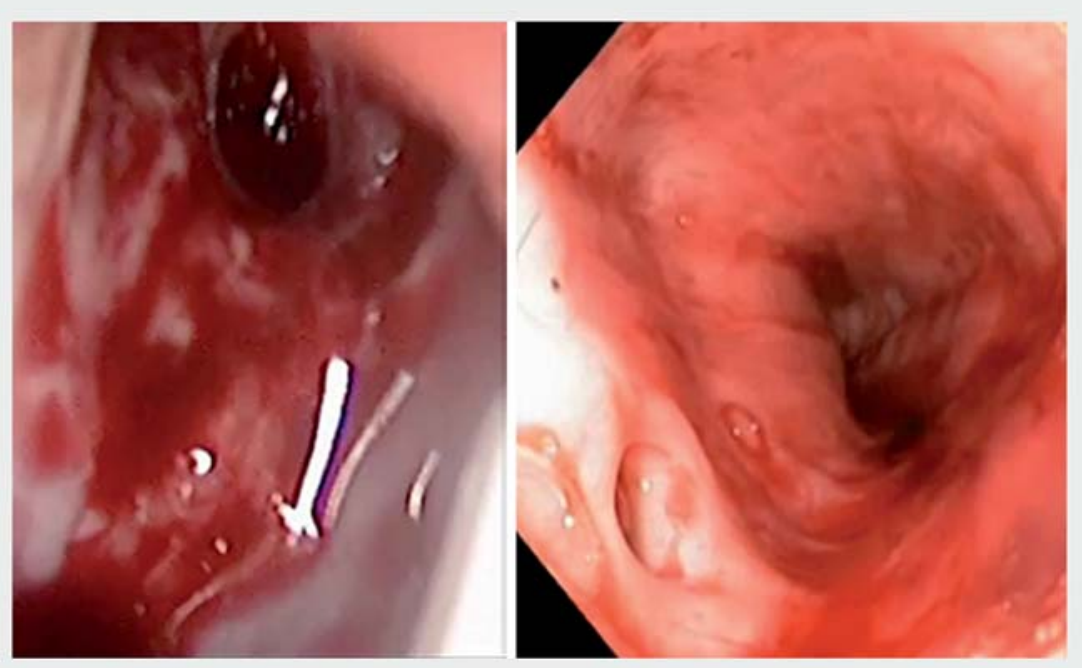

- Fig. 3 Surgery to repair the atrio-esophageal fistula. a The view of the defect from the heart. $\mathbf{b}$ The view of the fistula from the esophagus.

\section{References}

[1] Nair GM, Nery PB, Redpath C] et al. Atrioesophageal fistula in the era of atrial fibrillation ablation: a review. Can J Cardiol 2014; 30: $388-395$

[2] Singh SM, d'Avila A, Singh SK et al. Clinical outcomes after repair of left atrial esophageal fistulas occurring after atrial fibrillation ablation procedures. Heart Rhythm 2013; 10: $1591-1597$

[3] Mohanty S, Santangeli P, Mohanty P et al. Outcomes of atrioesophageal fistula following catheter ablation of atrial fibrillation treated with surgical repair versus esophageal stenting. J Cardiovasc Electrophysiol 2014; 25: 579-584

[4] Zellerhoff S, Lenze F, Schulz R et al. Fatal course of esophageal stenting of an atrioesophageal fistula after atrial fibrillation ablation. Heart Rhythm 2011; 8: 624-626

\section{Ignacio Couto-Worner, MD}

Servicio de Aparato Digestivo, Complexo Hospitalario Universitario de A Coruña, As Xubias de Arriba 84, 15006 A Coruña, Spain Fax: +34-981-222222

ignacio.couto.worner@sergas.es

\section{Bibliography}

DOI https://doi.org/10.1055/s-0043-115217

Published online: 18.7.2017

Endoscopy 2017; 49: E250-E251

(c) Georg Thieme Verlag KG

Stuttgart · New York

ISSN 0013-726X

\section{ENDOSCOPY E-VIDEOS}

https://eref.thieme.de/e-videos

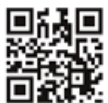

Endoscopy E-Videos is a free access online section, reporting on interesting cases and new

techniques in gastroenterological endoscopy. All papers include a high quality video and all contributions are freely accessible online.

This section has its own submission website at

https://mc.manuscriptcentral.com/e-videos 